This is an open access article under the CC BY-NC-ND license (https://creativecommons.org/licenses/by-nc-nd/3.0/) Issue III, November 2020

ISSN 2707-9481

ISBN 978-601-323-207-2

https://doi.org/10.31643/2020.022

Irina Petrovna Selezneva

Krasnoyarsk State Pedagogical University named after Viktor Astafiev, Russian Federation

E-mail: selezneva@kspu.ru

ORCID ID 0000-0002-1590-9482;

Researcher ID: O-9894-2018
Vlada Vladimirovna Vlasova

Krasnoyarsk State Pedagogical University named after Viktor Astafiev, Russian Federation

E-mail: 116vlasovavv@kspu.ru

ORCID ID 0000-0002-3339-0063

\title{
Content and Language Integrated Learning (CLIL) for gifted children: Music and English
}

\begin{abstract}
In the article is considered the formation of an educational milieu for teaching gifted children by introducing elements of Content and Language Integrated Learning into the educational milieu on the example of an integrated lesson in Music and English. The article analyzes the "Three-ring model of giftedness" by J. Renzulli and its modification carried out by J. F. Feldhusen and K. Heller; the "theory of investment" in the creative process by R. Sternberg. As a part of the research, a Music and English lesson for students of the 2nd grade on the topic "New year" was developed using elements of the method of Content and Language Integrated Learning (CLIL), including musical and rhythmic exercises, chanting, dance, game activities. The authors of the article conclude that an interdisciplinary approach to building a creative educational milieu for teaching gifted children is effective, which contributes to expanding the range of the students' individual opportunities.
\end{abstract}

Keywords: educational milieu, giftedness, Content and Language Integrated Learning, Music, English.

Cite this article as: Selezneva I. P., Vlasova V. V. (2020). Predmetno-yazykovoye integrirovannoye obucheniye (CLIL) odarennykh detey: muzyka i angliyskiy yazyk [Content and Language Integrated Learning (CLIL) for gifted children: Music and English]. Challenges of Science. Issue III, p.: 154-158. (In Russian). https://doi.org/10.31643/2020.022

Ирина Петровна Селезнева

ФГБОУ ВО «Красноярский Государственный

Педагогический Университет им. В.П.

Астафьева», Российская Федерация

E-mail: selezneva@kspu.ru

ORCID: 0000-0002-1590-9482;

Researcher ID: O-9894-2018
Влада Владимировна Власова

ФГБОУ ВО «Красноярский Государственный

Педагогический Университет им. В.П.

Астафьева», Российская Федерация

E-mail: 116vlasovavv@kspu.ru

ORCID ID 0000-0002-3339-0063

\section{Предметно-языковое интегрированное обучение (CLIL) одаренных детей: музыка и английский язык}

Абстракт. В статье рассматривается формирование образовательной среды для обучения одаренных детей путем внедрения в образовательное пространство элементов предметно-языкового интегрированного 
обучения на примере интегрированного урока по музыке и английскому языку. Анализируется «Трехкольцевая модель одаренности» Дж. Рензулли и ее модификация, проведенная Дж.Ф. Фельдхьюсеном и К. Хеллером; "теория инвестирования" в творческий процесс Р. Стернберга. В рамках исследования разработан урок по музыке и английскому языку для обучающихся 2 класса по теме «Новый год» с использованием элементов методики предметно-языкового интегрированного обучения (CLIL), включающий музыкально-ритмические упражнения, распевки, танцевально-игровую деятельность. Авторы статьи приходят к выводу об эффективности междисциплинарного подхода к построению творческой образовательной среды для обучения одаренных детей, способствующего расширению спектра индивидуальных возможностей обучающихся.

Ключевые слова: образовательная среда, одаренность, предметно-языковое интегрированное обучение, музыка, английский язык.

В настоящее время большое внимание уделяется развитию одаренных детей и модернизации системы работы с ними, появляются новые методики и технологии, позволяющие развивать природные способности одаренных обучающихся эффективнее, чем раньше.

Под одаренностью понимается системно развивающееся в течение жизни качество психики, которое определяет возможность достижения человеком более высоких (необычных, незаурядных) результатов в одном или нескольких видах деятельности по сравнению с другими людьми [4].

Над исследованием одаренности работали такие ученые, как Дж. Рензулли, К. Хеллер, Дж. Ф. Фельдхьюсеном, С. Райс, Л. Смит, А.Г. Асмоловым, В.Г. Грязевой-Добшинской, А.М. Матюшкина, А.И. Савенкова, Д.Б. Богоявленской и др.

Одной из первых моделей развития одаренности считается «Трехкольцевая модель одаренности» Дж. Рензулли, которая включает следующие параметры: высокий уровень интеллектуального развития, креативность и увлеченность задачей. Метод «Трех видов обогащения учебной программы» Дж. Рензулли, направленный на развитие одаренности в процессе обучения, состоял из трех этапов: расширение круга интересов обучающихся, развитие мышления обучающихся, проведение самостоятельной исследовательской работы и решение творческих задач. Данную модель впоследствии усилил Дж.Ф. Фельдхьюсен, добавив в нее структуру Я-Концепции индивида [1].

Многофакторная модель К. Хеллера, построенная на основе «Трехкольцевой модели одаренности», включает, помимо компонетнов, указанных Дж. Рензулли, фактор образовательной среды как решающий фактор в развитии одаренных детей.

Н.А. Спичко характеризует образовательную среду как совокупность психологического, социального и пространственно-предметного факторов, куда входят также материальный фактор и межличностные отношения [1].

Следует отметить, что в развитии одаренных детей основной функцией образовательной среды принято считать создание возможности как для раскрытия еще не проявившихся интересов и способностей, так и для развития уже проявившихся способностей обучающихся.

Одной из задач развития одаренности в рамках образовательной среды выделяют развитие субъектности обучающегося. Детский возраст является сензитивным для развития одаренности, поскольку от успешного развития потенциально одаренного ребенка зависит, перерастет ли одаренность в устойчивое качество личности или останется особенностью возрастного развития, которое многие ученые называют «феноменом вундеркиндов».

Условия для развития одаренности могут быть внешними и внутренними. К внешним относится образовательная среда со всеми ее составляющими, к внутренним - личные качества и стремления обучающегося. Внутренние условия включают такие качества личности обучающегося, как упорство, настойчивость, целеустремленность, высокая работоспособность, организованность и высокий уровень мотивации.

Внешние и внутренние условия развития одаренности тесно взаимосвязаны. Образовательная среда, опираясь на качества личности обучающихся, обеспечивает его личностное развитие.

Образовательная среда формируется при создании ориентационного поля развития, предусматривающего творческое участие обучающегося, его способность к организации и самоорганизации.

Творческий подход рассматривается учеными как основной для обучения одаренных детей. Р. Стернберг создал «теорию инвестирования», согласно которой творческий процесс можно рассматривать как удачное инвестирование капитала с позиции «покупать дешево, продавать 
дорого». Согласно теории Р. Стернберга, существует шесть факторов, влияющих на творческие проявления: интеллект (способность), знание, стиль мышления, индивидуальные черты личности, мотивация и внешняя среда. Для творчества важными являются следующие составляющие интеллекта: синтетическая способность - умение увидеть проблему по-новому, преодолеть границы обыденного незнания; аналитическая способность - выявление идей для дальнейшей разработки; практические способности - умение убеждать других в ценности идей, т.е. умение «продать» другим творческую идею [1].

В отечественной психологии проблемы развития одаренности рассматриваются обычно в контексте исследований творчества и творческого мышления. А.М. Матюшкин подходит к проблеме одаренности с точки зрения творческого потенциала индивида. Он считает, что в основе одаренности лежит не интеллект, а творческий потенциал. Творческий потенциал личности, являясь основой одаренности, не реализуется автоматически, без условий жизни и социального окружения [3].

Влияние учителя на обучающегося является ключевым фактором развития одаренности. Учитель обеспечивает комплексность и системность развития одаренности во время обучения в рамках учебной программы, стимуляцию познавательных способностей и интересов обучающихся, создание на уроке атмосферы вдохновения и ситуации успеха. Поддержка педагогом творческих идей обучающихся и помощь в их осуществлении играет решающую роль в поддерживании стремлений обучающегося к самосовершенствованию, поскольку потребность в самореализации у одаренных детей чрезвычайно высока. Действуя не по принципу «принятия другого», а выстраивая общение с обучающимися в авторитарном стиле, педагог рискует привести одаренного ребенка к стагнации его развития как одаренной личности и, как следствие, к потере интереса обучающегося к исследованию и творчеству.

Одним из основополагающих предметов в рамках творческого образования одаренных обучающихся является музыка. Опыт эмоционально-образного восприятия музыки как фундамента для дальнейшего изучения искусства в целом и музыки в частности чрезвычайно важен именно в детском возрасте, поскольку от развития образного и ассоциативного мышления, формирования ценностно-смысловых ориентаций и духовно-нравственных ориентиров, на развитие которых направлены уроки музыки, напрямую зависит дальнейшее обучение ребенка и становление его как личности.

В детском возрасте доминирует игровая деятельность, в связи с этим образовательная программа по музыке включает такие приемы, как развивающие игры, упражнения на развитие чувства ритма и на отработку музыкально-ритмических движений, хороводы, пляски, а также прослушивание музыки и пение под аудиозапись или живой аккомпанемент учителя.

Хотелось бы отметить, что в условиях образования одаренных детей создаются общеобразовательные программы, которые включают сразу несколько предметов и нацелены на то, чтобы материал, пройденный в рамках одного предмета, был переработан и повторен - в ином ракурсе - в рамках изучения другого предмета. Такие программы строятся на метопредметных и межпредметных связях с применением специальных частных методик, к которым может быть отнесено предметно-языковое интегрированное обучение (CLIL).

CLIL (Content and Language Integrated Learning) относится к любому сфокусированному на двух предметах образовательному контексту, в котором дополнительный язык, т.е. не основной язык, на котором ведется весь курс обучения, используется как средство при обучении неязыковому предмету [2].

Д. Марш, один из ведущих специалистов в сфере билингвального обучения и полилингвизма университета Финляндии Ювяскюля, создал акроним CLIL для обозначения новой методики. По словам Д. Марша, необходимость применения CLIL в Европе в 1994 году была обусловлена развитием политической и образовательной сферы - внедрение в практику академической и социальной мобильности в Евросоюзе требовало достижения высокого уровня иноязычной компетенции. С начала своего существования акроним CLIL стал самым используемым методическим термином в Европе для обозначения программ интеграции обучения иностранному языку и предметному содержанию. В 2005 году Д. Марш предложил использовать термин CLIL как общий термин для различных методологий двустороннего характера, в которых внимание уделялось тематическому содержанию и изучаемому языку. В 2007 году методика CLIL начала применяться в 20 европейских странах: чаще всего на уровне среднего звена и начального образования. На данный момент во многих университетах Европы действуют курсы подготовки преподавателей CLIL, coздана Европейская рамка квалификации для преподавателей, которые практикуют данную технологию в обучении неязыковым предметам [2]. 
Основные принципы методики CLIL изложены Д. Койлом и описываются аббревиатурой «4C», которая обозначает Content (Содержание), Communication (Коммуникация), Cognition (Познание) и Culture (Культура). Успешный урок по данной методике должен сочетать в себе элементы всех принципов. Краткая характеристика принципов методики CLIL может быть представлена следующим образом:

- Содержание. Развитие знаний, умений и навыков предметной области.

- Коммуникация. Использование иностранного языка во время обучения общеобразовательному предмету.

- Познание. Развитие познавательных и мыслительных способностей, формирующих общее представление о мире.

- Культура. Представление себя как части культуры и осознания альтернативных культур [2].

В рамках исследования разработан урок по музыке и английскому языку для обучающихся 2 класса по теме «Новый год», включающий элементы методики CLIL.

Образовательные:

Цели проекта:

Обучение определению характера, настроения музыкального произведения;

Закрепление англоязычного словарного запаса;

Закрепление навыков танцевальных движений.

Развивающие:

Развитие эмоциональной отзывчивости;

Развитие навыков чистого интонирования, выразительного исполнения знакомых песен;

Развитие воображения, творческой фантазии;

Развитие навыков хорового пения;

Воспитательные:

Воспитание внимательности и усидчивости.

Метод обучения - репродуктивный. Речевой материал - лексика на английском языке по теме «Новый год». Для реализации проекта необходимы проектор, компьютер, динамики.

Занятие начинается с приветственного слова учителя и музыкально-ритмических упражнений, например, упражнения «Всадник».

Следующим этапом занятия является диалог с обучающимися. Учитель спрашивает о том, какое сейчас время года и какой самый любимый праздник в этом времени года у детей. Обучающиеся отвечают, что сейчас зима и любимый праздник - это Новый год.

Далее идет повторение уже ранее разученного новогоднего танца под музыку «Jingle Bells». Обучающиеся танцуют, учитель контролирует их деятельность и подсказывает правильные движения, исправляет ошибки. Этот этап позволяет закрепить навыки танцевальных движений и дать обучающимся возможность проявить двигательную активность.

Этап распевки считается основополагающим перед процессом пения, на данном этапе используется упражнение «Часы».

После распевки обучающиеся приступают к процессу изучения песни и пению с помощью видеоролика - https://www.youtube.com/watch? $\mathrm{v}=0$ _WkKAxS02A\&feature=emb_logo. Для работы с видео понадобятся компьютер, проектор и динамики. Предполагается, что на уроке английского языка обучающиеся проработали все неизвестные лексические единицы, которые могли вызвать трудности при чтении или воспроизведении. Песня на английском языке является элементом предметно-языкового интегрированного обучения - на уроке музыки, обучающиеся сначала разучивают слова песни, повторяя за исполнителем на видео, потом поют с ним вместе. Во время прослушивания они отбивают ладонями ритм и поют хором. Учитель направляет деятельность обучающихся, координируя их ритмические движения во время работы с песней.

Заключительным этапом урока является подвижная игра «Баба Яга». Поскольку игра является ведущим видом деятельности для обучающихся этого возраста, целесообразно включать игровые элементы в состав урока.

В конце урока учитель проводит рефлексию путем опроса через закрытые вопросы. Например, «Понравился ли вам урок?».

Важно отметить, что учитель музыки также должен владеть английским языком, чтобы он мог исправлять ошибки в произношении обучающихся и отвечать на их вопросы. 
Таким образом можно сделать вывод о том, что урок музыки и английского языка с использованием элементов предметно-языкового интегрированного обучения соответствует целям и задачам современного обучения и может быть использован в образовательных программах для развития одаренных детей.

Ссылка на данную статью: Селезнева И. П., Власова В. В. (2020) Предметно-языковое интегрированное обучение (CLIL) одаренных детей: музыка и английский язык. Материалы Международной практической интернет-конференции «Актуальные проблемы науки» [Challenges of Science]. Выпуск III, стр. 154-158. https://doi.org/10.31643/2020.022

\section{Литературы}

[1] Glukhova, V.A. (2020) Social-pedagogical ways for developing giftedness in the process of education. Chelyabinsk, Vestnik SUSU.17, 4-8.

[2] Marsh D. (2012) Content and Language Integrated Learning: The European Dimension - Actions, Trends and Foresight Potential. Jyvaskyla, University of Jyvaskyla, 20-24.

[3] Matyushkin, A.M. (2014) Aptitude and Age. Encouraging a Gifted Child's Creative Potentials. Moscow, SPS «MODEK» Publishing House, 138-139.

[4] Pedagogical Encyclopedia: Modern Notions of Contemporary Pedagogics. (2003) Under the Editorship of N.N. Tulkibaeva, L.V. Trubaychuk. Moscow, «Vostok» Publishing House, 5-6.

\section{References}

[1] Glukhova, V.A. (2020) Social-pedagogical ways for developing giftedness in the process of education. Chelyabinsk, Vestnik SUSU.17, 4-8.

[2] Marsh D. (2012) Content and Language Integrated Learning: The European Dimension - Actions, Trends and Foresight Potential. Jyvaskyla, University of Jyvaskyla, 20-24.

[3] Matyushkin, A.M. (2014) Aptitude and Age. Encouraging a Gifted Child's Creative Potentials. Moscow, SPS «MODEK» Publishing House, 138-139.

[4] Pedagogical Encyclopedia: Modern Notions of Contemporary Pedagogics. (2003) Under the Editorship of N.N. Tulkibaeva, L.V. Trubaychuk. Moscow, «Vostok» Publishing House, 5-6. 